\title{
Stress-strain dependence for soy-protein nanofiber mats
}

\author{
S. Khansari, ${ }^{1}$ S. Sinha-Ray, ${ }^{1}$ A. L. Yarin ${ }^{1,2, a)}$ and B. Pourdeyhimi ${ }^{3}$ \\ ${ }^{1}$ Department of Mechanical and Industrial Engineering, University of Illinois at Chicago, 842 W. Taylor St., \\ Chicago IL 60607-7022, USA \\ ${ }^{2}$ Center for Smart Interfaces, Technische Universität Darmstadt Petersen str. 32, 64287 Darmstadt, Germany \\ ${ }^{3} 3427$ The Nonwovens Institute, Box 8301, North Carolina State University, Raleigh NC 27695-8301, USA
}

(Received 3 December 2011; accepted 4 January 2012; published online 24 February 2012)

\begin{abstract}
Soy protein/nylon 6 monolithic and core-shell nanofibers were solution-blown and collected on a rotating drum as fiber mats. Tensile tests of rectangular strips of these mats revealed their stress-strain dependences. These dependences were linear at low strains which correspond to their elastic behavior. Then, a plastic-like nonlinearity sets in, which is followed by catastrophic rupture. Parameters such as Young's modulus, yield stress, and specific strain energy were measured. The results were rationalized in the framework of the phenomenological elastic-plastic model, as well as a novel micromechanical model (the latter attributes plasticity to bond rapture between the individual overstressed fibers in the mat). Besides, the effects of stretching history, rate of stretching, and winding velocity of the collector drum on the strength-related parameters are studied. The results for soy protein/nylon 6 nanofiber mats are also compared to those for solution blown pure nylon 6 mats, which were produced and tested in the same way. (C) 2012 American Institute of Physics. [doi:10.1063/1.3682757]
\end{abstract}

\section{INTRODUCTION}

Booming SoyDiesel production ${ }^{1,2}$ facilitates increasing production of soy, while using only soy oil (which comprises only about $20 \%$ of soy mass), and leaving behind abundant residual soy protein. In addition to the use of soy protein as a nutrient, it has great industrial value too. In particular, developing innovative ways of utilizing residual soy protein resulting from SoyDiesel production will make the overall process more economically feasible and reduce cost of SoyDiesel. Moreover, these innovative soy protein-based products will help to significantly reduce dependence on oil, not only for transportation but also by replacing petroleum-based polymers by their biopolymer counterparts. Biopolymer products are even more attractive than those derived from petroleum, since the former are biodegradable, while the latter are not. Non-biodegradable packaging and other materials create significant problem with garbage utilization, and their burning contributes to production of greenhouse gases. Biodegradable materials produced from residual soy protein effectively eliminate this problem. The field where biodegradable materials can potentially replace petroleum-derived polymers encompasses textiles and nonwovens, biomedical, "green" construction and packaging materials, and catalyst supports.

One of potentially attractive ways of utilization of soy proteins is in production of novel "green" soy protein-based composites which is facilitated by their mechanical and thermal characterization. ${ }^{3}$ The first steps in the direction of utilization of soy protein resulting from SoyDiesel production have already delivered the first fruits in the field of nonwovens. Namely, nano-textured nonwovens have already been produced using solution blowing in. ${ }^{4}$ Moreover, a similar approach can be potentially applied to the other residuals of

\footnotetext{
a) Author to whom correspondence should be addressed. Electronic mail: ayarin@uic.edu. Tel.: (312) 996-3472.FAX: (312) 413-0447.
}

biofuel production: algae and other crops of interest. Soy protein nanofibers can be also produced by using a slower process, electrospinning. ${ }^{5-8}$ Both solution blowing and electrospinning employ blends of biodegradable soy protein and petroleumderived polymers to sustain spinnability of solutions employed.

The present work is devoted to the mechanical characterization of nano-textured nonwovens produced by using the solution blowing process similar to that of Ref. 4. The mechanical properties of soy blend or core-shell protein/nylon 6 nanofibers are also compared to those of pure nylon 6 nanofibers produced using solution blowing. The mechanical behavior revealed in the tensile tests is rationalized in the framework of two models, the standard phenomenological elasto-plastic model and the micromechanical model proposed in the present work. As a result, Young's modulus, the yield stress, and the corresponding micromechanical parameters of soy protein nanofiber mats are established, as well as the effect on them of such parameters as the rotational speed of the collector drum.

The paper is organized as follows. Materials and solutions used, sample preparation and tensile tests are described under Sec. II. Solution blown nanofiber mats are illustrated in the following section. Then Sec. IV outlines two different models used to describe stress-strain curves of soy protein/nylon 6 nanofiber mats and the details are given in Appendices $\mathrm{A}$ and $\mathrm{B}$. In the following section, the experimental data is compared with the models and the corresponding material parameters are established. Conclusions are drawn in Sec. VI.

\section{EXPERIMENTAL}

\section{A. Materials}

Materials used in this work include Polyamide-6 (nylon6) obtained from BASF $\left(M_{w}=65.2 \mathrm{KDa}\right)$, formic acid grade 
$>95 \%$, obtained from Sigma-Aldrich, protein isolate PROFAM 955 (SP 955) obtained from ADM Specialty Food Ingredients. All materials were used as received, without any further purification.

\section{B. Solution preparation}

For solution blowing of monolithic nanofibers of blend of soy protein and nylon 6 , the solution preparation was performed as described in Ref. 4. In particular, $1 \mathrm{~g}$ of soy protein SP 955 was mixed with $9.5 \mathrm{~g}$ of formic acid and left on a hotplate at $75^{\circ} \mathrm{C}$ for $24 \mathrm{~h}$. Next, $1.5 \mathrm{~g}$ of nylon 6 was added to the solution and stirred at $75^{\circ} \mathrm{C}$ for a day. For solution blowing of core-shell nanofibers, two solutions were prepared. The core solution was prepared as follows. First, $1.3 \mathrm{~g}$ of SP 955 was mixed with $8.7 \mathrm{~g}$ of formic acid and left on a hotplate at $75^{\circ} \mathrm{C}$ for $24 \mathrm{~h}$. Then, $1 \mathrm{~g}$ of nylon 6 was added to the solution and stirred on the hotplate at the same temperature for another day. The shell solution was a blend of $20 \mathrm{wt}$ $\%$ nylon 6 in formic acid, which was left on a hotplate at $75^{\circ} \mathrm{C}$ for a day to become homogeneous. For solution blowing of pure nylon 6 nanofibers, a $20 \mathrm{wt} \%$ solution of nylon 6 in formic acid was prepared.

\section{Solution blowing}

In order to produce soy protein-based nanofibers, the setup described in Ref. 4, 9-10 was used. In particular, for blowing of monolithic nanofibers, solution was pumped through a $13 \mathrm{G}$ needle using a syringe pump with flow rate of $5 \mathrm{ml} / \mathrm{h}$. After leaving the needle exit, the solution was subjected to a coaxial turbulent air jet at an upstream pressure of 1.5-2.5 bar through an annular nozzle surrounding the needle and the needle-to-collector distance was 19-24 cm. The upstream pressure differs from that of Ref. 10 since the tubing setting used in this particular experiment was $1 / 8$ ", whereas the tubing in Ref. 8 was $1 / 16$ ". Smaller tubing size caused more friction in the system; thus, higher upstream pressure was needed to obtain specific downstream velocity in Ref. 9-10. Solution blowing experiments were done at room temperature and $45 \%-55 \%$ relative humidity.

The set-up for core-shell co-blowing is described in Ref. 10. In particular, to blow core-shell soy protein/nylon 6 nanofibers, two different solutions were used as described above. The core solution was pumped into a central nozzle which was surrounded by a reservoir carrying the shell solution. The shell solution was pumped through the reservoir with the flow rate of $4 \mathrm{ml} / \mathrm{h}$. The core solution was supplied with the same flow rate. The core-shell jet was issued inside a concentric nozzle surrounded by an annular nozzle. A turbulent air jet was issued through the annular nozzle with the upstream pressure of 1.5 to 2.5 bar. It is emphasized that the exit of the core nozzle was slightly pushed inside the annular nozzle to avoid clogging. The core-shell soy protein/nylon 6 nanofibers were collected on a rotating drum covered with aluminum foil which was located $15 \mathrm{~cm}$ below the nozzle exit.

For comparison, solution blowing of pure nylon 6 was conducted as follows. Pure nylon 6 solution was pumped through a $13 \mathrm{G}$ needle with a flow rate of $5 \mathrm{ml} / \mathrm{h}$. The needle was surrounded by an annular nozzle. A turbulent air jet with the upstream pressure of 1.5 to 2.5 bar was issued through the annular nozzle. Nanofibers were collected on a rotating drum covered with aluminum foil located at a distance of 19-24 cm from the needle exit.

\section{Sample preparation}

Nanofibers were collected on a rotating drum with diameter of $5 \mathrm{~cm}$, which was covered with aluminum foil. The rotating drum had an angular velocity of 100-280 rad/s, which transcends into linear velocity of $2.5-7.0 \mathrm{~m} / \mathrm{s}$ at the foil surface. Aluminum foil which was covered with nanofiber mat was taken off from the rotating drum. The nanofiber mat was cut into rectangular pieces which were 25-35 $\mathrm{mm}$ long and 10 to $15 \mathrm{~mm}$ wide and then piled off from the foil. The thickness of nanofiber mat was $0.15-0.30 \mathrm{~mm}$. Nanofiber mat pieces which were used as samples in the uniaxial stretching experiments are shown in Fig. 1. The SEM images of the nanofiber mats are shown in Figs. 2(a), 2(b), 2(c). The samples were kept at room temperature and humidity.

\section{E. Tensile tests}

The tensile test was performed using a $100 \mathrm{~N}$ capacity Instron machine (model 5942). The upper and lower ends of the samples were clamped by Instron's pneumatic grips. The upper end was stretched with a single stretching rate $(0.1 \mathrm{~mm} / \mathrm{min})$, while the lower end was kept at its initial position. The uniaxial stretching tests were conducted until sample breakage. Tensile test with a fixed rate of stretching until sample rupture is termed protocol 1. This protocol was applied to soy protein/nylon 6 mats, pure nylon 6 mats, and core-shell nanofiber mats. Soy protein/nylon 6 nanofiber mats collected at different winding velocities of the rotating drum were also tested according to protocol 1. The corresponding mechanical properties of these nanofiber mats are reported below.

Another protocol, termed as protocol 2, was used to evaluate the effect of stretching rate in uniaxial stretching on mechanical behavior of nanofiber mats. Similar samples
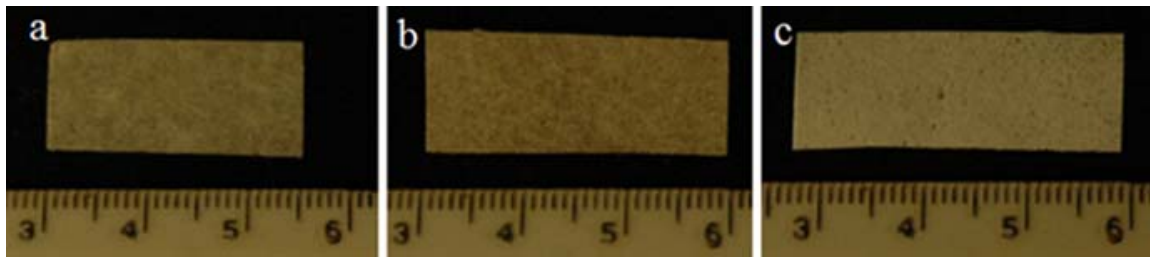

FIG. 1. (Color online) Solution blown nanofiber mat samples prepared for stretching test. Panel (a) shows soy protein/nylon 6 nanofibers. Panel (b) shows co-blown core-shell nanofibers, and panel (c) shows pure nylon 6 nanofibers. 

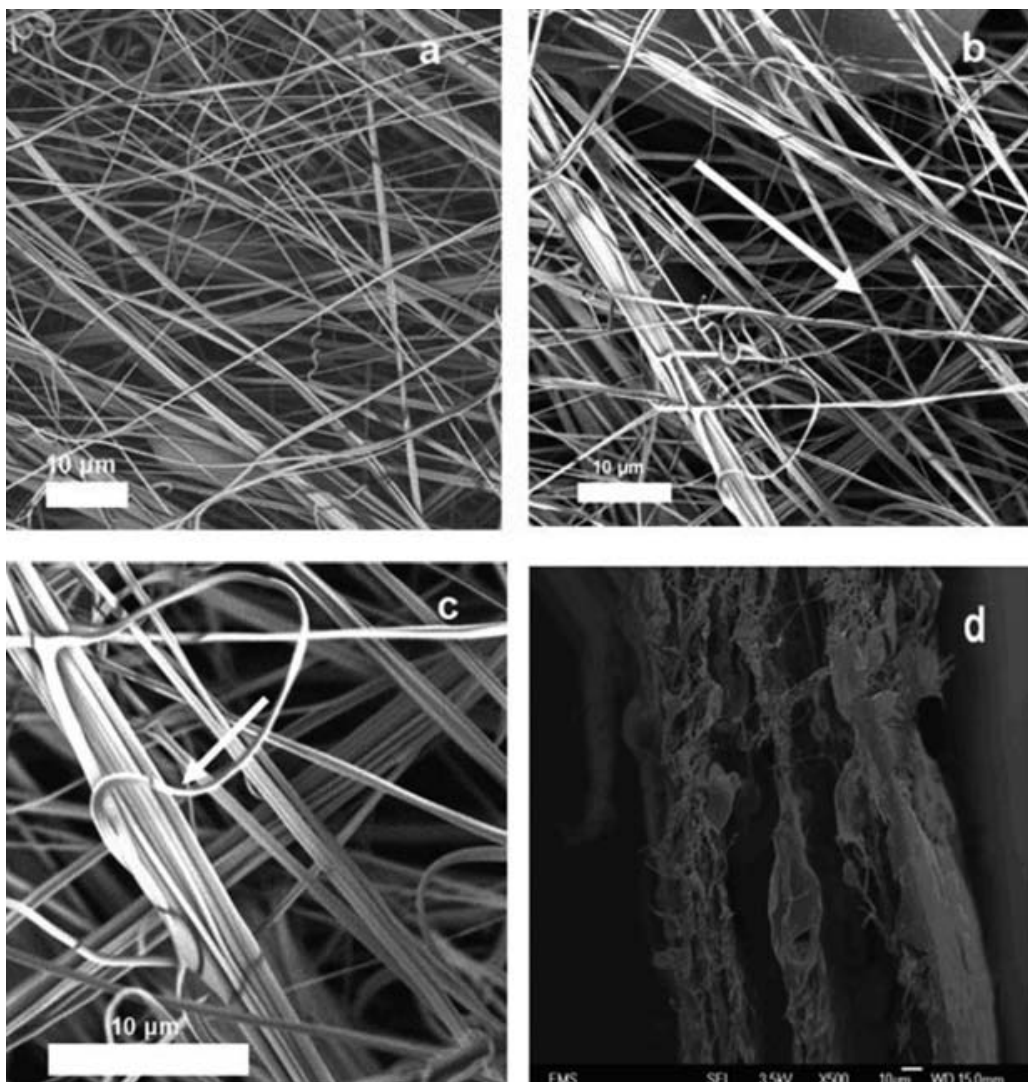

FIG. 2. SEM images of soy protein/nylon 6 nanofiber mat. Panel (a) shows that nanofibers collected on rotating drum are oriented. A zoomed-in image shown in panel (b) illustrates that stretched nanofibers are mostly oriented in the winding direction shown by an arrow. Panel (c) shows that some nanofibers are glued together, which is a result of an incomplete evaporation of solvent from the jet in flight. Panel (d) shows that nanofiber mats have a layered structure, and only about one half of the cross-section supports load in the uniaxial stretching tests. were tested with three different stretching rates: $0.1,0.5$, and $1.0 \mathrm{~mm} / \mathrm{min}$, and the corresponding mechanical properties were compared. This test was applied to soy protein/nylon 6 nanofiber mats.

The third set of experiments followed protocol 3, designed to evaluate the effect of pre-stretching on nanofiber mat's mechanical behavior. In particular, rectangular nanofiber samples were uniaxially stretched up to a particular strain (3\%), and were held at that strain for $5 \mathrm{~min}$. Then, they were released from the grips and fully unloaded. After that, they were clamped again with the initial gauge length and stretched. Then, the unloading and the following stretching were repeated once again. At the third stretching, the

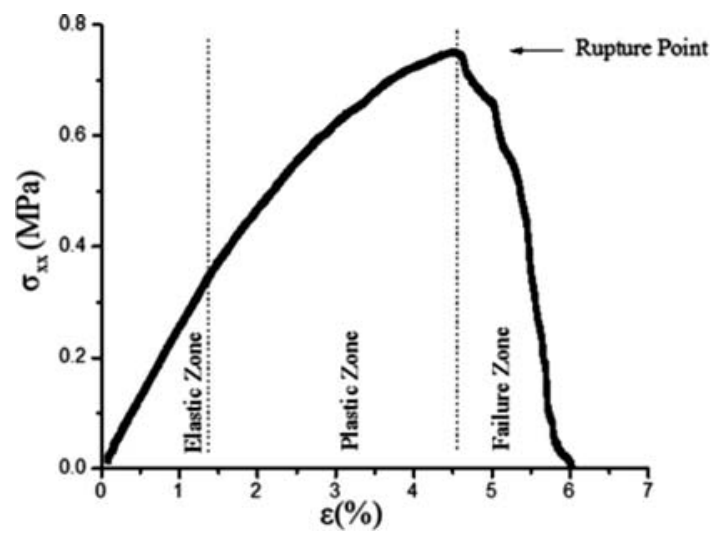

FIG. 3. Tensile stress vs strain acquired for a sample of soy protein/nylon 6 solution-blown nanofiber mat. Symbols-experimental data. Sample rupture occurs at $\sigma_{x x, \text { rupture }}=0.7 \mathrm{MPa}$ and $\varepsilon_{\text {rupture }}=4.5 \%$. process was continued to the sample failure. This protocol was applied to soy protein/nylon 6 nanofiber mats.

In the experiments which followed protocol 4, samples were uniaxially stretched with incremental loads of $0.01 \mathrm{~N}$ and unloaded afterwards. The loading and unloading procedure continued until a sample was stretched with $0.35 \mathrm{~N}$ load. This test protocol was designed to evaluate reversible and irreversible components in the mechanical behavior of nanofiber mats. This test was conducted with soy protein/nylon 6 nanofiber mats.

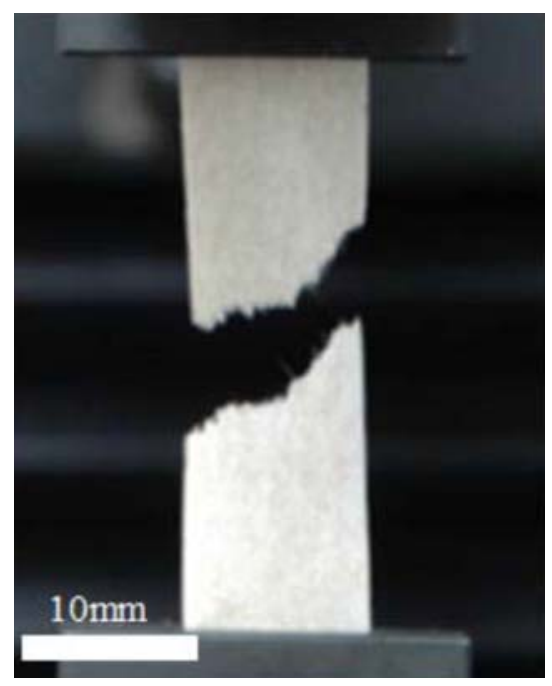

FIG. 4. (Color online) Typical sample rupture pattern for soy protein/nylon 6 nanofiber mat. 

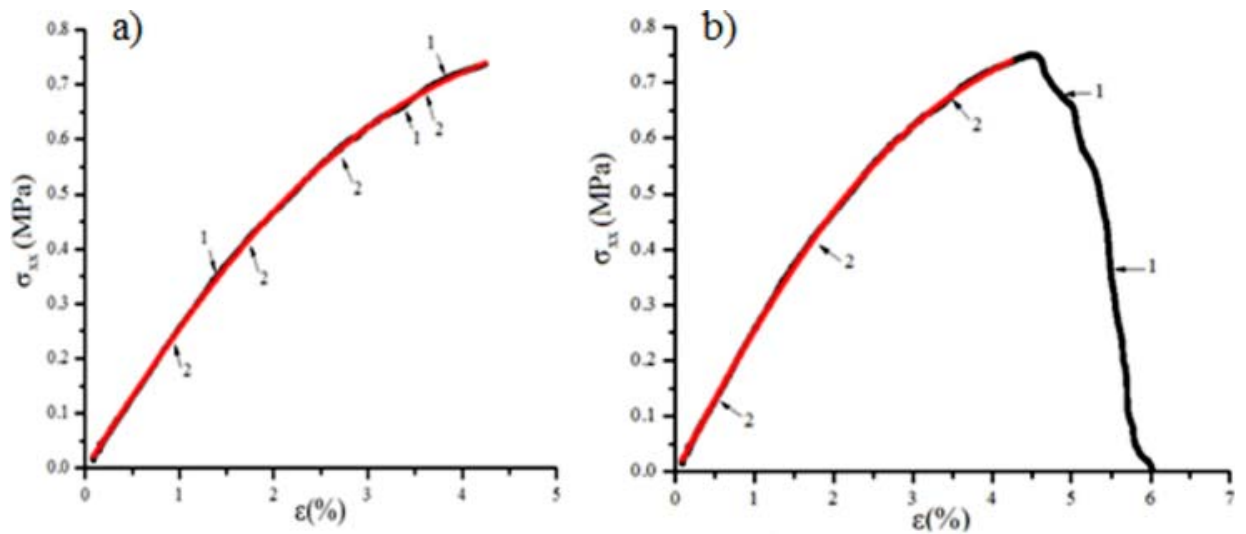

FIG. 5. (Color online) Comparison of phenomenological elastic-plastic model [Eq. (1)] with the experimental stressstrain data for soy protein/nylon 6 nanofiber mat. In panel (a), Eq. (1) is fitted to the experimental data up to the rupture point. Panel (b) shows the overall stressstrain data corresponding to panel (a). Symbols 1: (black in color) experimental data, line 2: (red in color) phenomenological model, Eq. (1).

\section{OBSERVATIONS OF SOLUTION BLOWN MATS}

Morphology of solution-blown nanofibers was observed by using a Phenom scanning electron microscope (SEM). For the observation purposes, soy protein/nylon 6 nanofiber mats were sputter coated with a 6-7 nm Pd-Pt layer. The observations were done by using $5 \mathrm{kV}$ accelerating voltage. The observations of soy protein/nylon 6 nanofiber mat cross-section were done by using JEOL JSM $6320 \mathrm{~F}$ scanning microscope after a $7-8 \mathrm{~nm}$ Pd-Pt layer was sputter coated. In these observations a $3.5 \mathrm{kV}$ accelerating voltage was applied.

Solution-blown nanofibers had cross-sectional diameters in the range of 300-500 $\mathrm{nm}$. The size distribution of the nanofibers corresponded to the one reported in Ref. 4. The overall and zoomed-in SEM images of soy protein/nylon 6 nanofibers collected on a rotating drum are shown in Fig. 2. Compared to those of Ref. 4, nanofibers are stretched and have preferential orientation in the direction of rotation [cf. Figs. 2(a) and 2(b)], since they were collected on a rotating drum. Due to the relatively small distance between the needle exit and rotating drum, solvent did not completely evaporate from the jet in flight. As a result, nanofibers were glued to each other in some places of the collected mat [cf. Fig. 2(c)].

The mat cross-section shown in Fig. 2(d) demonstrates that it has a layered structure and is not fully filled with nanofibers. There are significant gaps between the fiber layers. This circumstance should be accounted for when calculating the stress supported by nanofiber mats in uniaxial elongation by using Instron. The images similar to the one in Fig. 2(d) taken at 30 different locations will be used for correcting the cross-sectional area and evaluating the real area which supports load. The processing of such images by using MATLAB revealed that only about $50 \%$ of the crosssectional area in the mat contains nanofibers which support the load.

\section{THEORETICAL BACKGROUND}

The phenomenological equation for the uniaxial stretching of a planar strip as in the experiments in the present work yields the following, the stress-strain dependence

$$
\sigma_{x x}=\sqrt{\frac{8}{3}} Y \tanh \left(\sqrt{\frac{2}{3}} \frac{E}{Y} \varepsilon\right)
$$

which encompasses the elastic and plastic behavior (see Appendix A). In Eq. (1), $E$ is Young's modulus, $Y$ is the yield stress, $\sigma_{x x}$ is the tensile stress, and $\varepsilon$ is the tensile strain.

In the following section, Eq. (1) will be compared to the experimental data to establish the values of Young's modulus $E$ and the yield stress $Y$ for solution-blown soy protein nanofiber mats.

The micromechanical stress-strain relation for nanofiber mats under uniaxial elongation derived in Appendix B reads

$$
\begin{aligned}
\sigma_{x x}= & E_{m} \varepsilon \frac{1}{2 \pi} \exp (2 \varepsilon) \int_{0}^{2 \pi} \cos ^{4} \varphi\left(1+\frac{2 E_{f} \varepsilon \cos ^{2} \varphi}{\sigma_{*}}\right) \\
& \times \exp \left(-\frac{2 E_{f} \varepsilon \cos ^{2} \varphi}{\sigma_{*}}\right) \frac{d \varphi}{\left[\cos ^{2} \varphi+\exp (4 \varepsilon) \sin ^{2} \varphi\right]}
\end{aligned}
$$

The dimensionless tensile strength $\sigma * / E_{f}$ in Eq. (2) affects the character of deviation of the dependence of $\sigma_{x x}$ on $\epsilon$ from the linear Hooke's law, and thus effectively controls mat plasticity.

In the limit of small strains when $\varepsilon \rightarrow 0$, Eq. (2) reduces to $\sigma_{x x}=(3 / 8) E_{m} \varepsilon$. The latter corresponds to Hookean behavior. The Hookean limit should correspond to that of the phenomenological model of Eq. (1), which means that $E_{m}=(32 / 9) E$. Equation (2) is compared to the experimental data in the following section.

TABLE I. Average mechanical properties of soy protein/nylon 6 nanofiber mats.

\begin{tabular}{lccccc}
\hline \hline & $\begin{array}{c}\text { Average thickness } \\
\text { of the samples } \\
(\mathrm{mm})\end{array}$ & $\begin{array}{c}\text { Average Young's } \\
\text { modulus } E(\mathrm{MPa})\end{array}$ & $\begin{array}{c}\text { Average yield } \\
\text { stress } Y(\mathrm{MPa})\end{array}$ & $\begin{array}{c}\text { Average specific } \\
\text { strain energy } u \\
(\mathrm{MPa})\end{array}$ & $\begin{array}{c}\text { Average maximum } \\
\text { strain at rupture } \\
\varepsilon_{\text {rupture }}(\%)\end{array}$ \\
\hline 12.07 & 0.20 & $19.56 \pm 6.48$ & $0.56 \pm 0.15$ & $2.26 \pm 0.71$ & $\begin{array}{c}\text { Average maximum } \\
\text { stress at rupture } \\
\sigma_{x x, \text { rupture }}\end{array}$ \\
\hline \hline
\end{tabular}



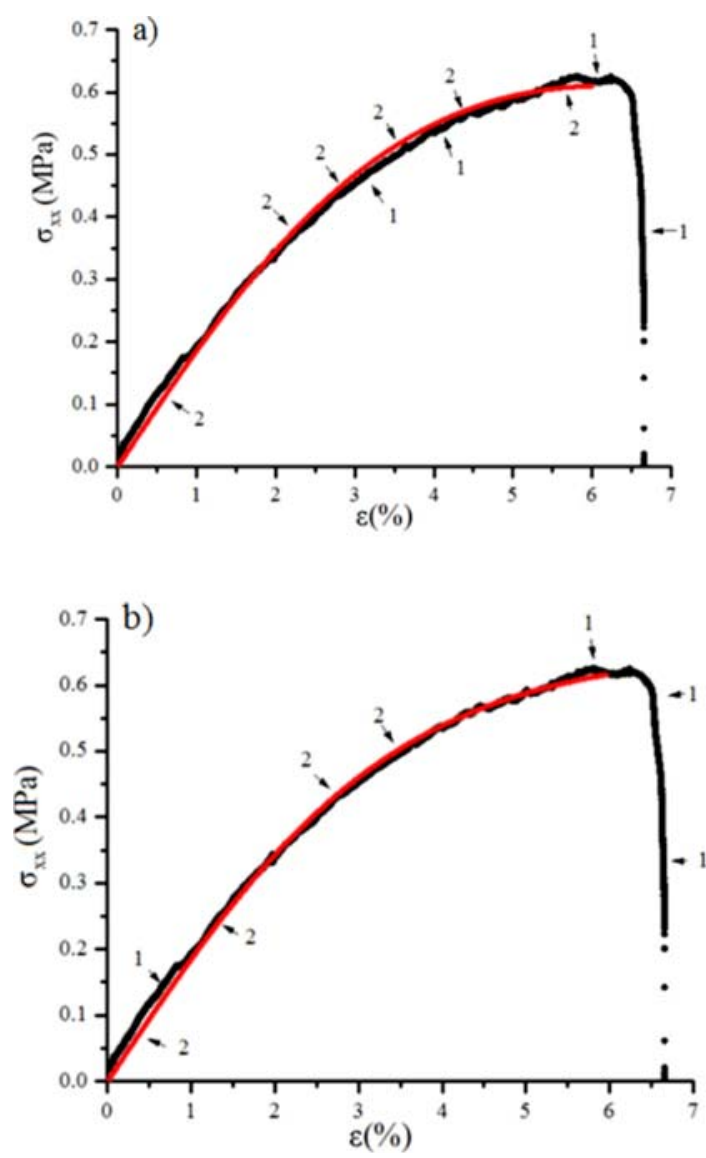

FIG. 6. (Color online) Soy protein/nylon 6 stress-strain curve fitted with (a) phenomenological and (b) micromechanical models. Sample No. 1 from Table II. Symbols 1 (black in color) depict the experimental data, lines 2 (red in color) the corresponding theoretical results.

\section{COMPARISON WITH THE EXPERIMENT AND DISCUSSION}

\section{A. Stress-strain curves from the experiments according to protocol 1 (monolithic fibers)}

A typical stress-strain dependence for soy protein/nylon 6 nanofiber mats measured in the tests following protocol 1, is shown in Fig. 3. It is seen that at relatively small deformations, $\sigma_{x x}$ depends on $\epsilon$ practically linearly demonstrating an elastic Hookean response. At higher strains, $\varepsilon>1.5 \%$, the response becomes nonlinear which can be attributed to the onset of plasticity.

The morphology of sample failure corresponding to Fig. 3, is illustrated in Fig. 4. In most cases, samples failed in the middle (cf. Fig. 4). Typically, the failure stress and strain were in the range of $\sigma_{x x, \text { rupture }}=0.4-0.9 \mathrm{MPa}$ and $\varepsilon_{\text {rupture }}=4 \%-10 \%$, respectively.

Fitting Eq. (1) to the experimental stress-strain curve in the elastic and plastic zone, the values of Young's modulus $E$ and the yield stress $Y$ can be determined (cf. Fig. 5). The average values of $E$ and $Y$ found for several samples of soy protein/nylon 6 nanofiber mats are listed in Table I. The table also contains the specific strain energy defined as $u=\int_{0}^{\varepsilon} \sigma_{x x} d \varepsilon$.

The micromechanical model (2) was also fitted to the data, and one case of such fitting is shown in Fig. 6. It is seen that the micromechanical model fits the data in the elastic and plastic part of the stress-strain dependence as good as the phenomenological model (1), albeit as the latter is incapable to describe the last part corresponding to the catastrophic rupture of the sample. Similar comparisons were done for 20 different samples and the results are presented in

TABLE II. Young's modulus, yield stress, and the relative bond-rupture stress $\sigma_{*} / E_{f}$. Soy protein/nylon 6 nanofiber mats.

\begin{tabular}{|c|c|c|c|c|c|c|}
\hline Sample & Width (mm) & Thickness (mm) & $\begin{array}{l}\text { Young's modulus } E \\
\text { (phenomenological } \\
\text { model); } \mathrm{MPa}\end{array}$ & $\begin{array}{l}\text { Young's modulus } E \\
\text { corresponding to the } \\
\text { micromechanical } \\
\text { model; } \mathrm{MPa}\end{array}$ & $\begin{array}{l}\text { Yield stress of the } \\
\text { phenomenological } \\
\text { model, } Y(\mathrm{MPa})\end{array}$ & $\begin{array}{c}\text { Relative bond rupture stress } \\
\text { of the micromechanical } \\
\text { model, } \sigma_{*} / E_{f}\end{array}$ \\
\hline 1 & 11.91 & 0.22 & 12.8 & 12.8 & 0.53 & 0.071 \\
\hline 2 & 11.47 & 0.22 & 17.58 & 17.58 & 0.46 & 0.047 \\
\hline 3 & 12.43 & 0.22 & 14.26 & 14.26 & 0.46 & 0.058 \\
\hline 4 & 11.47 & 0.22 & 20.88 & 20.88 & 0.53 & 0.047 \\
\hline 5 & 11.21 & 0.22 & 19.69 & 19.69 & 0.6 & 0.055 \\
\hline 6 & 11.38 & 0.24 & 24.01 & 24.01 & 0.6 & 0.047 \\
\hline 7 & 11.53 & 0.2 & 38.02 & 38.02 & 0.78 & 0.038 \\
\hline 8 & 11.65 & 0.22 & 24.25 & 24.25 & 0.53 & 0.041 \\
\hline 9 & 11.99 & 0.22 & 14.87 & 14.87 & 0.49 & 0.058 \\
\hline 10 & 12.01 & 0.16 & 21.79 & 21.79 & 0.79 & 0.060 \\
\hline 11 & 11.59 & 0.16 & 21.58 & 21.58 & 0.69 & 0.062 \\
\hline 12 & 11.68 & 0.22 & 17.62 & 17.62 & 0.59 & 0.057 \\
\hline 13 & 10.87 & 0.22 & 21.93 & 21.93 & 0.49 & 0.042 \\
\hline 14 & 11.6 & 0.22 & 14.55 & 14.55 & 0.56 & 0.062 \\
\hline 15 & 12.72 & 0.22 & 18.74 & 18.74 & 0.67 & 0.062 \\
\hline 16 & 13.38 & 0.16 & 14.58 & 14.58 & 0.69 & 0.076 \\
\hline 17 & 14.14 & 0.16 & 20.22 & 20.22 & 0.39 & 0.041 \\
\hline 18 & 13.44 & 0.17 & 40.28 & 40.28 & 0.77 & 0.035 \\
\hline 19 & 12.83 & 0.15 & 16.50 & 16.50 & 0.21 & 0.030 \\
\hline 20 & 12.29 & 0.18 & 21.46 & 21.46 & 0.57 & 0.041 \\
\hline
\end{tabular}


TABLE III. Average mechanical properties of soy protein/nylon 6 nanofiber mats found for three different rates of stretching.

\begin{tabular}{lccccc}
\hline \hline $\begin{array}{l}\text { Rate of stretching } \\
(\mathrm{mm} / \mathrm{min})\end{array}$ & $\begin{array}{c}\text { Average Young's } \\
\text { modulus } E(\mathrm{MPa})\end{array}$ & $\begin{array}{c}\text { Average yield } \\
\text { stress } Y(\mathrm{MPa})\end{array}$ & $\begin{array}{c}\text { Average specific strain } \\
\text { energy } u(\mathrm{MPa})\end{array}$ & $\begin{array}{c}\text { Average maximum strain } \\
\left.\text { at rupture } \epsilon_{\text {rupture }} \%\right)\end{array}$ & $\begin{array}{c}\text { Average maximum stress } \\
\text { at rupture } \sigma_{x x, \text { rupture }}\end{array}$ \\
\hline 0.1 & $19.56 \pm 6.48$ & $0.56 \pm 0.15$ & $2.26 \pm 0.71$ & $4.52 \pm 0.92$ & $0.67 \pm 0.10$ \\
0.5 & $21.52 \pm 1.82$ & $0.57 \pm 0.03$ & $2.85 \pm 0.36$ & $4.57 \pm 0.14$ & $0.75 \pm 0.08$ \\
1.0 & $31.13 \pm 6.88$ & $0.65 \pm 0.12$ & $2.99 \pm 0.02$ & $4.04 \pm 0.2$ & $1.12 \pm 0.41$ \\
\hline \hline
\end{tabular}

Table II. The fitted values of $E_{m}$ of the micromechanical model were recalculated into the values of Young's modulus $E$ of the phenomenological model using the relation $E_{m}=(32 / 9) E$, and found to be in full agreement with the values of $E$ found directly by fitting the phenomenological model (Table II). It is emphasized that the micromechanical model (2) does not involve the yield stress $Y$. Instead, it involves the relative characteristic bond-breaking stress $\sigma_{*} / E_{f}$, which is responsible for plastic effects. Its values for 20 samples are also presented in Table II.

The effect of the relative fiber rupture parameter $\sigma_{*} / E_{f}$ on predictions of the micromechanical model is illustrated in Fig. 7, which shows how a particular value of this parameter is chosen to fit the data in the plastic part when the value of $E_{m}$ (or $E$ ) has already been established using the elastic part of the stress-strain curve.

\section{B. Effect of the stretching rate according to protocol 2 (monolithic fibers)}

Performing tensile test on soy protein/nylon 6 nanofiber mats with three different stretching rates, it was found that unaixial stretching with a higher stretching rate results in a higher value of Young's modulus corresponding to the stress-strain curve. Also, the yield stress, strain energy, and maximum stress at rupture acquire higher values for higher stretching rates. Table III contains such results for three different stretching rates. The corresponding graphic illustration of the above-mentioned trends is depicted in Fig. 8. The pa-

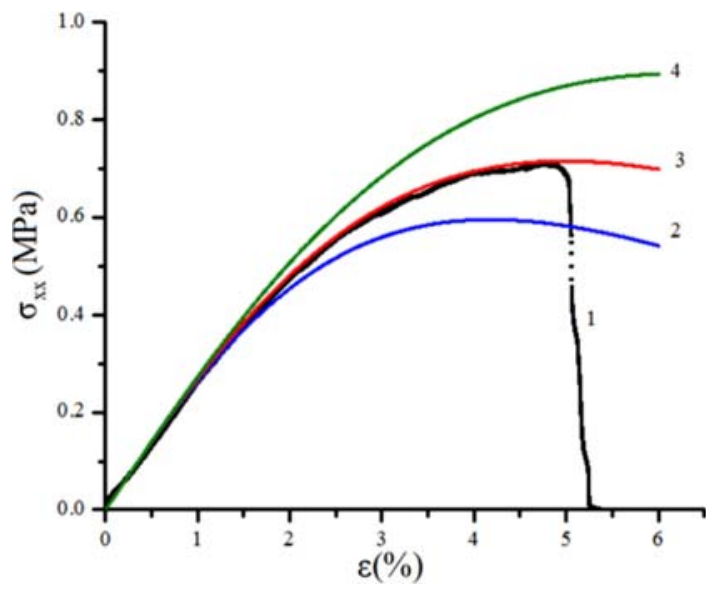

FIG. 7. (Color online) The effect of the relative fiber rupture stress, $\sigma_{*} / E_{f}$, on modeling plastic behavior of soy protein/nylon 6 nanofiber mats. Black symbols (1) depict the experimental data. Curves 2, 3, and 4 show the results of the micromechanical model with different values of the ratio $\sigma_{*} / E_{f}: 2$ $\sigma_{*} / E_{f}=0.040,3-\sigma_{*} / E_{f}=0.047$, and $4-\sigma_{*} / E_{f}=0.058$. rameters listed in Table III and Fig. 8 were found by fitting the phenomenological Eq. (1) to the experimental stressstrain curves.
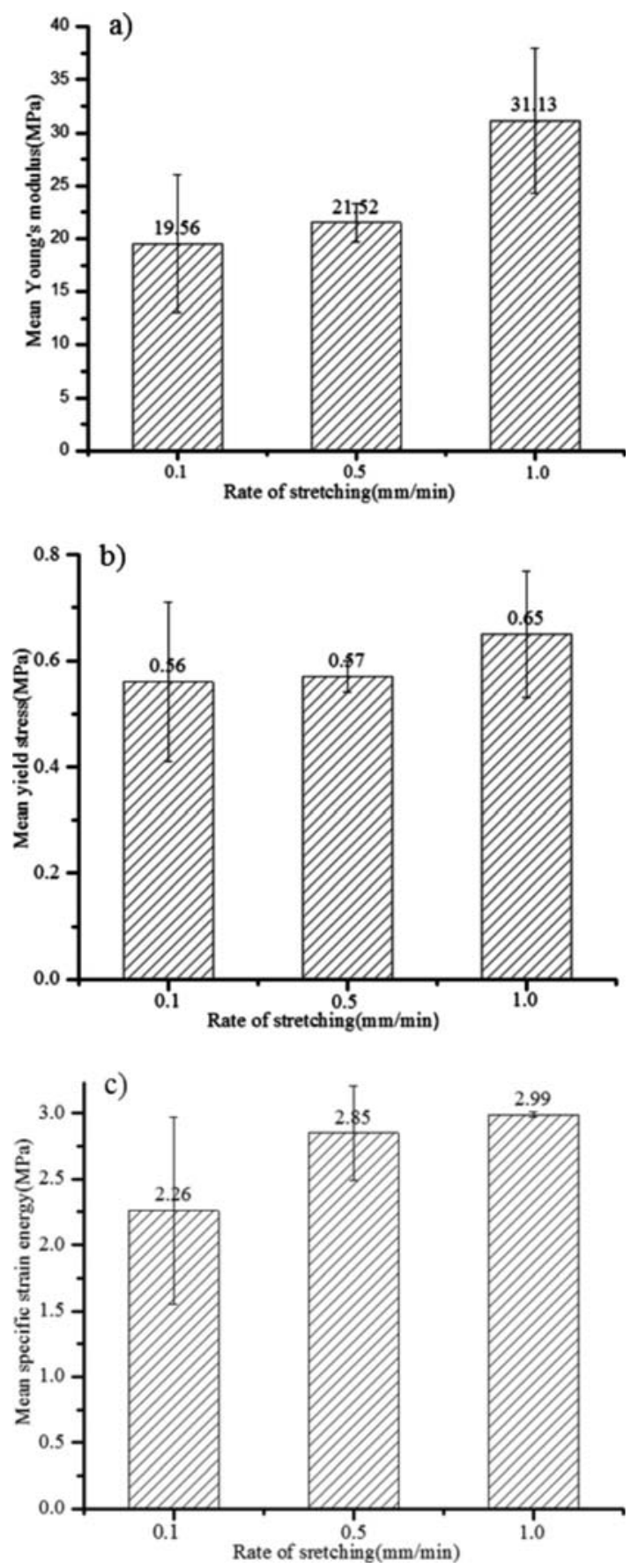

FIG. 8. (a) Young's modulus, (b) yield stress, and (c) specific strain energy for three different rates of stretching. 
TABLE IV. Average Young's moduli for soy protein/nylon 6 nanofiber samples for three consequent stretching tests.

\begin{tabular}{|c|c|c|c|c|}
\hline $\begin{array}{l}\text { Average } \\
\text { thickness of } \\
\text { the samples } \\
(\mathrm{mm})\end{array}$ & $\begin{array}{l}\text { Average } \\
\text { width of the } \\
\text { samples } \\
(\mathrm{mm})\end{array}$ & $\begin{array}{l}\text { Average } \\
\text { Young's } \\
\text { modulus E } \\
(\mathrm{MPa}), 1 \text { st } \\
\text { stretching }\end{array}$ & $\begin{array}{l}\text { Average } \\
\text { Young's } \\
\text { modulus } E \\
(\mathrm{MPa}), 2 \text { nd } \\
\text { stretching }\end{array}$ & $\begin{array}{l}\text { Average } \\
\text { Young's } \\
\text { modulus } E \\
(\mathrm{MPa}), \text { 3rd } \\
\text { stretching }\end{array}$ \\
\hline 0.17 & 13.28 & $21.19 \pm 9.45$ & $26.74 \pm 13.30$ & $24.60 \pm 10.54$ \\
\hline
\end{tabular}

\section{Effect of pre-stretching on the stress-strain curves of soy protein/nylon 6 nanofiber mats according to protocol 3 (monolithic fibers)}

According to protocol 3, soy protein/nylon 6 nanofiber mat was loaded up to $3 \%$ strain and held at this strain for $5 \mathrm{~min}$. Then, the sample was released and clamped again at the same gauge length. After that, the second pre-stretching step was done up to 3\% strain where the sample was kept for 5 min. Then, it was released once again and reclamped with the initial gauge length. After that, the sample was stretched up to its rupture. The phenomenological model (1) was fitted to the stress-strain curves for the $1^{\text {st }}, 2^{\text {nd }}$, and $3^{\text {rd }}$ stretching and the corresponding values of Young's moduli found are reported in Table IV and Figs. 9 and 10. The results show that pre-stretching increases nanofiber mat strength, and in particular, Young's modulus at the $2^{\text {nd }}$ consequent stretching. Figure 9 and the data for the $2^{\text {nd }}$ and $3^{\text {rd }}$ stretching in Table IV show that the highest value of Young's modulus can be reached in the intermediate $\left(2^{\text {nd }}\right)$ stretching process instead of the last $\left(3^{\text {rd }}\right)$ one. This could be attributed to damage accumulated in the preceding two stretching tests, as a result of which many fibers in the mat can already be ruptured before the 3rd test had begun.

\section{Incremental loading-unloading of soy protein/nylon 6 nanofiber mats according to protocol 4 (monolithic fibers)}

An example of the experimental data obtained following protocol 4 with alternating loading and unloading is shown in Fig. 11. The experiments of this type allow

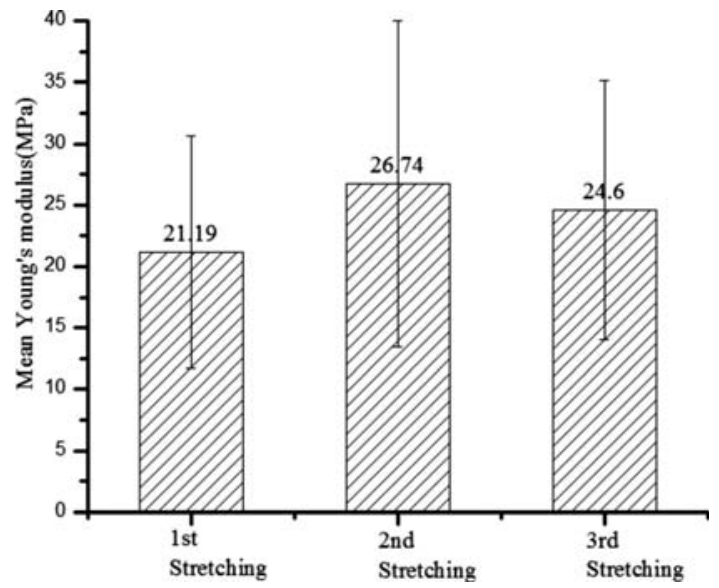

FIG. 9. Young's moduli in three consequent stretching tests.

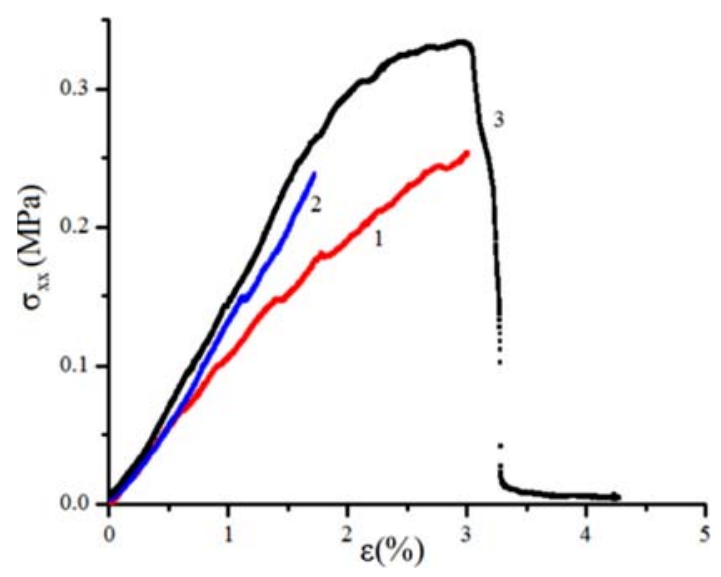

FIG. 10. (Color online) Stress-strain curves for soy protein/nylon 6 nanofiber mat in three subsequent stretching tests. Data set 1 shows the results for the $1^{\text {st }}$ stretching; 2 : for the $2^{\text {nd }}$ stretching; and 3: for the $3^{\text {rd }}$ stretching.

evaluation of the reversibility/irreversibility of sample deformation. In particular, Fig. 11(a) shows the stressstrain curve obtained in the loading steps of the experiment, in which sample was loaded by incremental values of $0.01 \mathrm{~N}$. After each loading step, the sample was
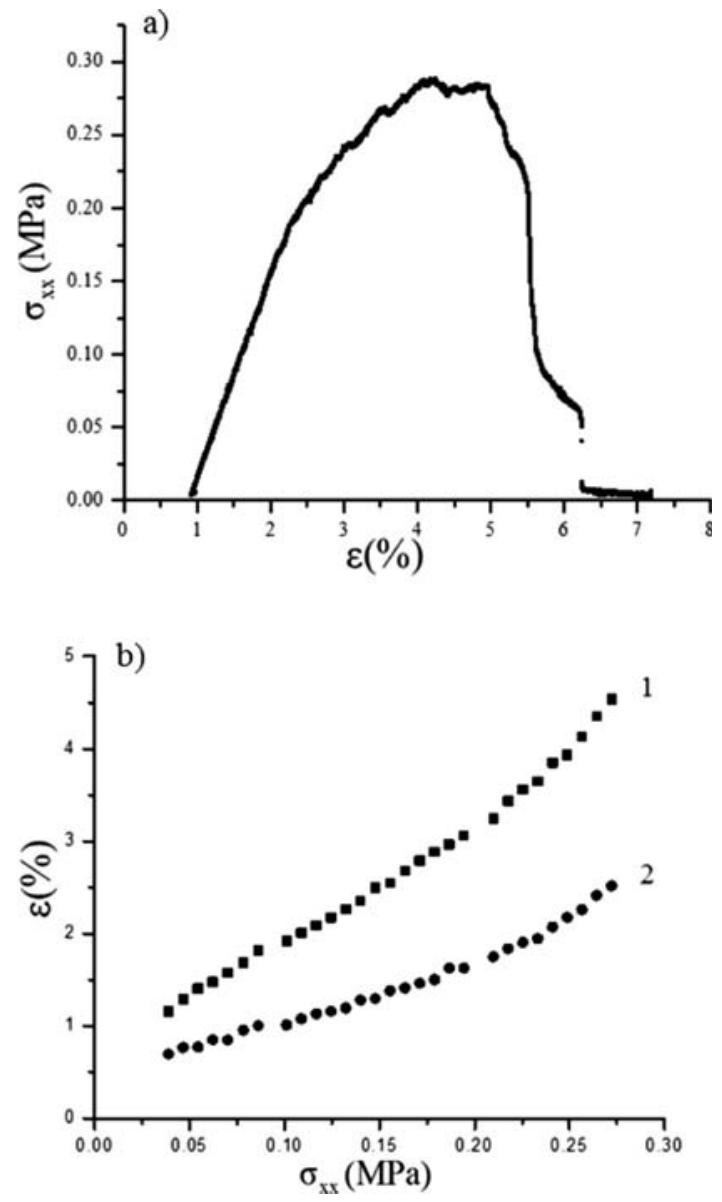

FIG. 11. (a) Stress-strain curve corresponding to the loaded states of sample according to protocol 4. (b) Strain vs stress: square symbols (1) show the total strain vs the applied stress, circular symbols (2) show the corresponding irreversible strain found in the unloaded sample. 


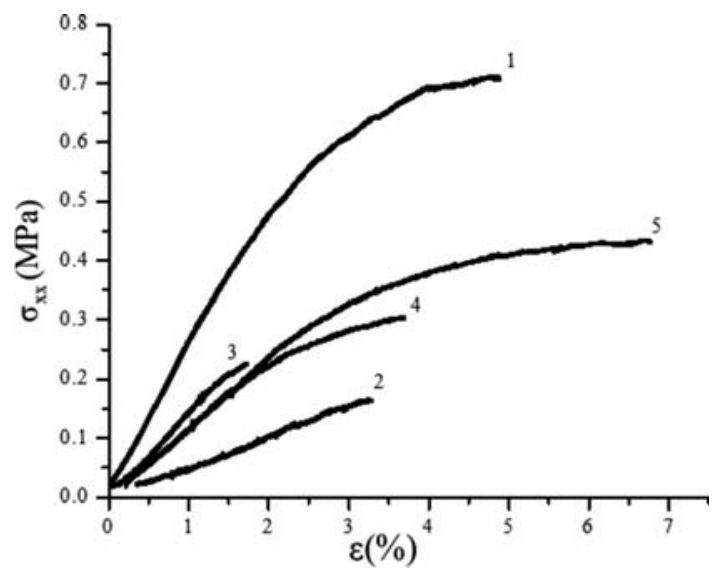

FIG. 12. Stress-strain curves at different winding velocities at sample formation. Data set 1 corresponds to the winding velocity of $3.2 \mathrm{~m} / \mathrm{s} ; 2$ : to 3.6 ; 3 : to 4.5 ; 4 : to 5.5 ; and 5 : to $6.9 \mathrm{~m} / \mathrm{s}$.

unloaded, and shrank, but not to its initial length due to some irreversible changes in the mat structure. That allowed us to evaluate the irreversible strain corresponding to each stress level achieved, as is shown in Fig. 11(b). This incremental loading and unloading was continued up to $0.35 \mathrm{~N}$, which is close to the rupture point. It is seen that the irreversible part of strain corresponding to plastic component due to the damage accumulation is gradually increasing as the total strain and the applied stress increase.

\section{E. Effect of winding velocity on soy protein/nylon 6 nanofiber mats (monolithic fibers)}

Figure 12 shows stress-strain curves measured for samples corresponding to different winding velocities. The stress-strain curves were fitted with the phenomenological model (1) and, as a result, the values of Young's modulus and yield stress were found. They are listed in Table V together with the specific strain energy corresponding to the data sets in Fig. 12. These parameters are also illustrated graphically in Fig. 13. At the lowest values of the winding velocity the mat strength varies non-monotonously, being higher at 3.2 than at $3.6 \mathrm{~m} / \mathrm{s}$. However, beginning from the velocity of about $4.5 \mathrm{~m} / \mathrm{s}$ the further increase in the winding velocity practically does not affect the stress-strain curve (cf. Fig. 12). Overall, Figs. 12 and 13 show that the effect of the winding velocity in the intermediate range is insignificant.
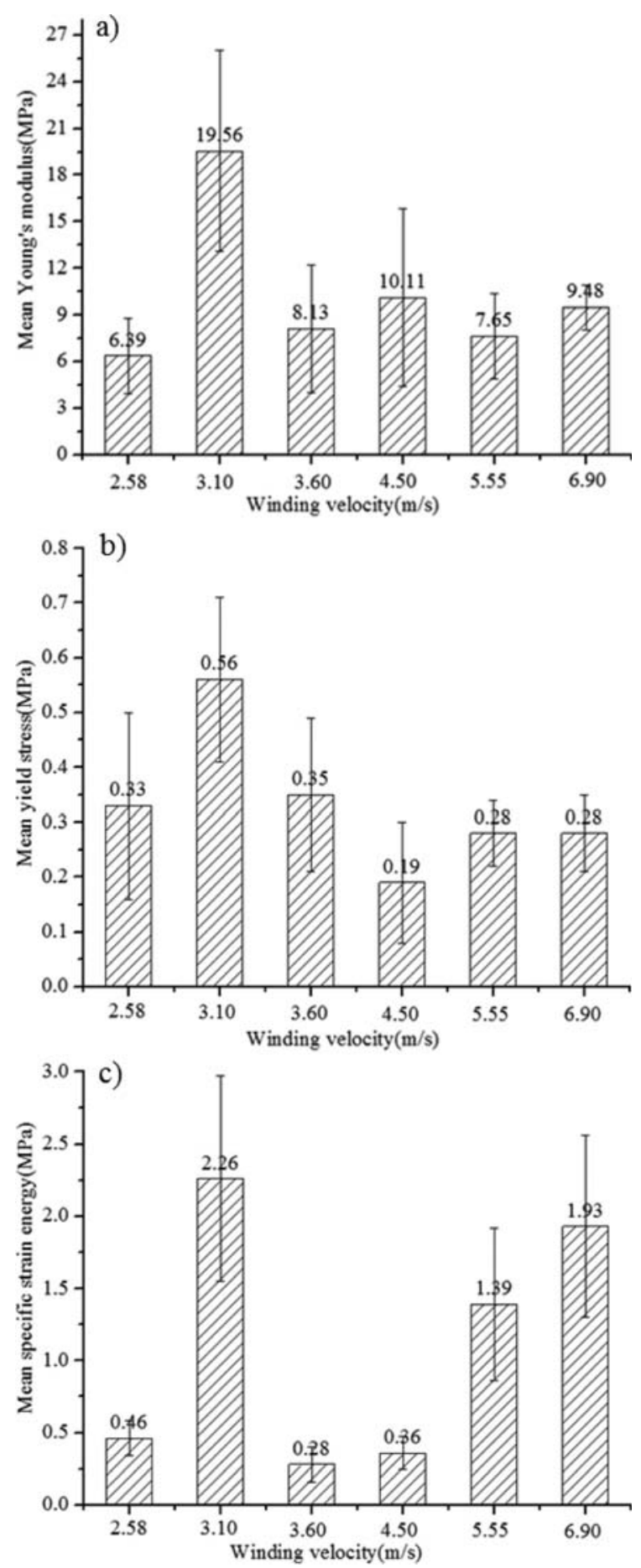

FIG. 13. Mechanical properties of soy protein/nylon 6 nanofiber mats at different winding velocities of mat formation.

TABLE V. Young's modulus, yield stress, and specific strain energy vs winding velocity at sample formation of soy protein/nylon 6 nanofiber mats.

\begin{tabular}{lcccc}
\hline \hline $\begin{array}{l}\text { Winding velocity } \\
(\mathrm{m} / \mathrm{s})\end{array}$ & $\begin{array}{c}\text { Average width of the } \\
\text { samples }(\mathrm{mm})\end{array}$ & $\begin{array}{c}\text { Average thickness of the } \\
\text { samples }(\mathrm{mm})\end{array}$ & $\begin{array}{c}\text { Average Young's } \\
\text { modulus } E(\mathrm{MPa})\end{array}$ & $\begin{array}{c}\text { Average yield } \\
\text { stress } Y(\mathrm{MPa})\end{array}$ \\
\hline 2.58 & 11.87 & 0.26 & $6.39 \pm 2.42$ & $0.33 \pm 0.17$ \\
3.1 & 12.07 & 0.20 & $19.56 \pm 6.48$ & $0.56 \pm 0.15$ \\
3.6 & 12.68 & 0.18 & $8.13 \pm 4.12$ & $0.35 \pm 0.14$ \\
4.5 & 11.97 & 0.16 & $10.11 \pm 5.71$ & $0.19 \pm 0.11$ \\
5.55 & 13.01 & 0.22 & $7.65 \pm 2.75$ & $0.28 \pm 0.06$ \\
6.9 & 13.41 & 0.21 & $9.48 \pm 1.46$ & 0.12 \\
energy $u(\mathrm{MPa})$ & $0.28 \pm 0.07$ & $1.36 \pm 0.11$ \\
\hline \hline
\end{tabular}




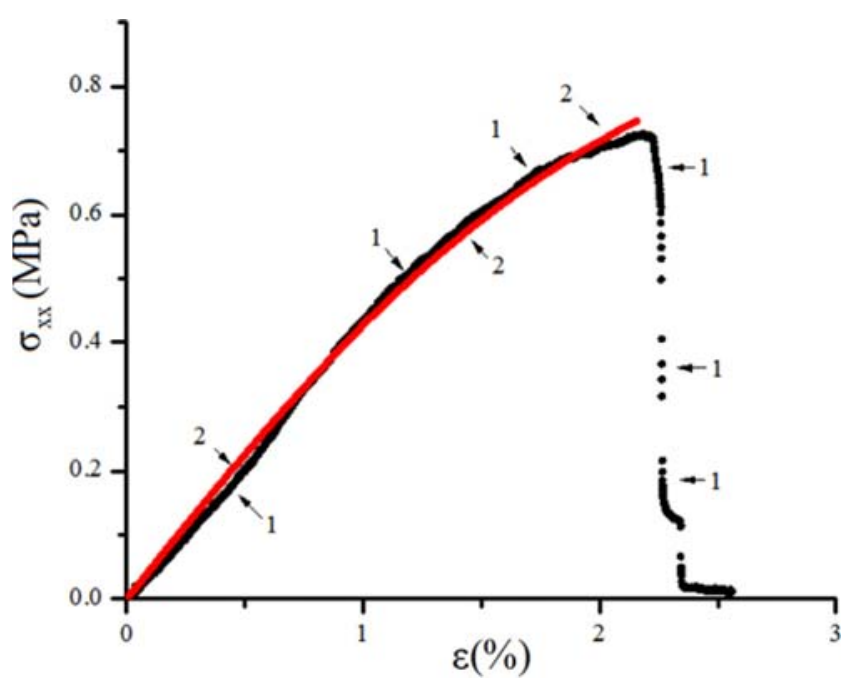

FIG. 14. (Color online) Stress-strain curve for soy protein-nylon 6 coreshell nanofiber mat (symbols 1 , black in color), fitted with the phenomenological model (line 2, red in color) up to the rupture point.

\section{F. Stress-strain curves from the experiments according to protocol 1 (core-shell nanofibers)}

Stretching behavior of core-shell soy protein/nylon 6 nanofiber mats was studied experimentally following protocol 1. A typical stress-strain data set is depicted in Fig. 14. Core-shell soy protein/nylon 6 nanofiber mats behave elastically at small strains. Plasticity is felt at the strains higher than about $1.5 \%$, and rupture occurs at about $\sigma_{x x, \text { rupture }}=0.4-0.7 \mathrm{MPa}$ and $\varepsilon_{\text {rupture }} \approx 2.1 \%$. Fitting the data by the phenomenological Eq. (1) revealed the values of the mechanical parameters listed in Table VI.

\section{G. Stress-strain curves from the experiments according to protocol 1 (nylon 6 nanofibers)}

For comparison with the data for monolithic and core-shell soy protein/nylon 6 nanofiber mats, pure nylon 6 mats were studied. A typical stress-strain curve for nylon 6 nanofiber mat is shown in Fig. 15. It was fitted with the phenomenological Eq. (1) and the corresponding mechanical parameters were established. Their values are listed in Table VII.

Comparing mechanical properties of soy protein/nylon 6 nanofiber mats with those of pure nylon 6 samples, we find that mean values of Young's modulus are almost the same for both types of samples [cf. Fig. 16(a)]. However, Figs. $16(\mathrm{~b})$ and 16(c) show that the specific strain energy and yield stress of pure nylon 6 nanofiber mats are higher than those of soy protein/nylon 6 nanofiber mats. Therefore, pure nylon 6 nanofiber mats resist more to deformation up to rupture than the corresponding soy protein/nylon 6 nanofiber mats.

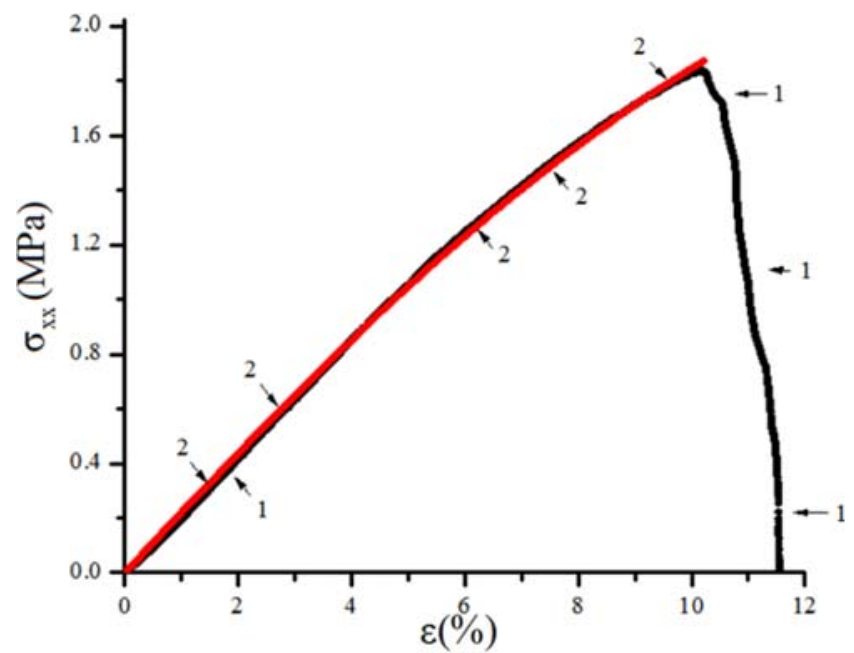

FIG. 15. (Color online) Stress-strain data (symbols 1, black in color) for pure nylon 6 nanofiber mat and the phenomenological model (line 2, red in color), fitted up to the rupture point (practically indistinguishable from the data).

\section{CONCLUSION}

The experiments conducted in this work showed that the novel monolithic and core-shell soy protein-containing nanofiber mats recently introduced by this group possess sufficiently high tensile strength for their applications as nonwovens. Their Young's moduli are close to those of pure nylon 6 nanofiber mats, albeit the yield stress and specific strain energy of the latter is higher. The effects of such governing parameters as winding velocity, as well as the stretching history on tensile strength of soy protein-containing nanofiber mats are also elucidated. It is shown that the traditional phenomenological and a novel micromechanical models (the latter is introduced in the present work) can successfully describe stress-strain curves of soy proteincontaining nanofiber mats in the elastic and plastic zones. These models are still incapable of describing the catastrophic rupture of such nanofiber mats at high values of tensile strain.

\section{ACKNOWLEDGMENTS}

This work was supported by a research contract with the United Soybean Board, Chesterfield, MO (research contract no. 0491).

\section{APPENDIX A: PHENOMENOLOGICAL CONSTITUTIVE EQUATION}

Phenomenological models which span the elastic and plastic ranges of stress response of solids to deformation date back to the seminal works of Prager, ${ }^{11,12}$ Truesdell, ${ }^{13,14}$ and Green. ${ }^{15}$ They bridge between the Hookean elastic body and the ideally plastic body which flows with a constant yield

TABLE VI. Mechanical properties of core-shell soy protein/nylon 6 nanofiber mats.

\begin{tabular}{lccccc}
\hline \hline $\begin{array}{l}\text { Average width of } \\
\text { the samples }(\mathrm{mm})\end{array}$ & $\begin{array}{c}\text { Average thickness of } \\
\text { the samples }(\mathrm{mm})\end{array}$ & $\begin{array}{c}\text { Average Young's } \\
\text { modulus } E(\mathrm{MPa})\end{array}$ & $\begin{array}{c}\text { Average yield } \\
\text { stress } Y(\mathrm{MPa})\end{array}$ & $\begin{array}{c}\text { Average specific } \\
\text { strain energy } u(\mathrm{MPa})\end{array}$ & $\begin{array}{c}\text { Average maximum strain } \\
\left.\text { at rupture } \varepsilon_{\text {rupture }} \%\right)\end{array}$ \\
\hline 11.22 & 0.15 & $22.26 \pm 6.06$ & $0.57 \pm 0.3$ & $0.92 \pm 0.02$ & $2.41 \pm 0.40$ \\
\hline \hline
\end{tabular}


TABLE VII. Mechanical properties of pure nylon 6 solution-blown nanofiber mats.

\begin{tabular}{|c|c|c|c|c|c|c|}
\hline $\begin{array}{l}\text { Average width of } \\
\text { the samples }(\mathrm{mm})\end{array}$ & $\begin{array}{c}\text { Average thickness of } \\
\text { the samples }(\mathrm{mm})\end{array}$ & $\begin{array}{l}\text { Average Young's } \\
\text { modulus } E(\mathrm{MPa})\end{array}$ & $\begin{array}{l}\text { Average yield } \\
\text { stress } Y(\mathrm{MPa})\end{array}$ & $\begin{array}{c}\text { Average specific } \\
\text { strain energy } u(\mathrm{MPa})\end{array}$ & $\begin{array}{c}\text { Average maximum } \\
\text { strain at rupture } \\
\varepsilon_{\text {rupture }}(\%)\end{array}$ & $\begin{array}{c}\text { Average maximum } \\
\text { stress at rupture } \\
\sigma_{x x, \text { rupture }}\end{array}$ \\
\hline 13.00 & 0.39 & $14.46 \pm 2.30$ & $1.17 \pm 0.75$ & $11.71 \pm 0.31$ & $11.80 \pm 1.39$ & $1.68 \pm 0.18$ \\
\hline
\end{tabular}
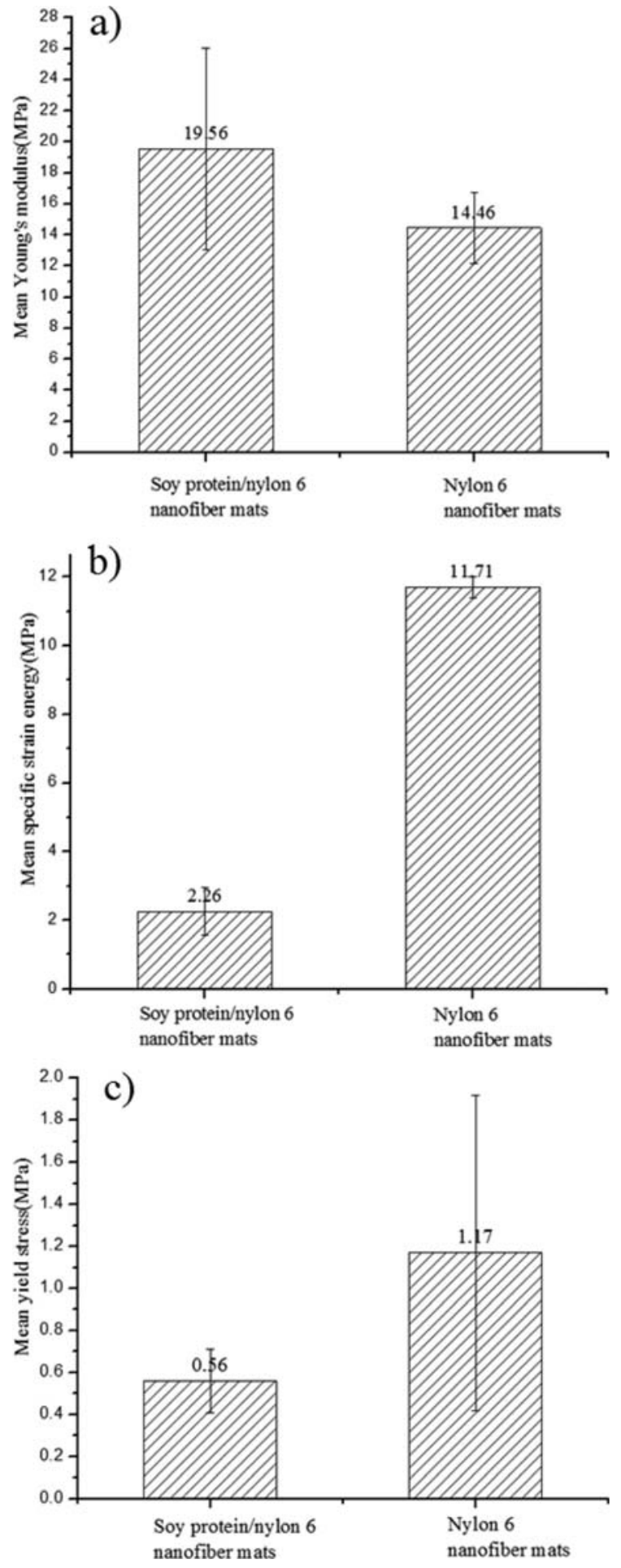

FIG. 16. (a) Average Young's moduli, (b) average specific strain energies, and (c) average yield stresses for soy protein/nylon 6 and pure nylon 6 solution-blown nanofibers. stress as soon as the von Mises condition is fulfilled. Different terms were applied to such materials, e.g., alternatively, hypo-elasticity or plasticity. More recently, materials of this type with deviations from the Hookean linear behavior and the associated irreversibility of deformation were understood as elastic-viscoplastic and close counterparts of viscoelastic polymeric liquids. ${ }^{16}$ Following Ref. 16, the phenomenological rheological constitutive equation prone of behavior reminiscent of that in Figs. 3 and 5 and 6 will be taken in the form

$$
\begin{aligned}
\frac{d \tau}{d t}= & \nabla \mathbf{v} \cdot \tau+\tau \cdot \nabla \mathbf{v}^{T}-\frac{2}{3}(\tau: \mathbf{D}) \mathbf{I}+2 \mu \mathbf{D}-\Gamma \tau \\
& -\frac{\alpha^{2} \Gamma}{\mu}\left[\tau^{2}-\frac{1}{3}\left(\tau^{2}: \mathbf{I}\right) \mathbf{I}\right],
\end{aligned}
$$

where $d / d t$ denotes the material time differentiation, $\tau$ denotes the deviatoric stress tensor, $\nabla \mathbf{v}$ is the velocity gradient tensor, and D its symmetric part (the rate-of-strain tensor), $\mathbf{I}$ is unit tensor, $\mu$ is the Lame coefficient responsible for the elastic behavior (in the case of an incompressible body assumed here, $\mu=E / 3$ with $E$ being Young's modulus), and $\tau: \mathbf{D}$ denotes the scalar product of two tensors. The dimensionless factor $\alpha^{2}$ is included here for the correspondence with Green's version of plastic rheological constitutive equation in Ref. 15.

In the uniaxial stretching of an axisymmetric specimen or a strip in the x-direction, the quantity $\Gamma$ in Eq. (A1) is determined as $\Gamma=\dot{\varepsilon}$ with $\dot{\varepsilon}=$ const being the rate of strain. Then, integrating Eq. (A1), we obtain for the longitudinal deviatoric stress

$$
\tau_{x x}=\frac{2 \mu}{\alpha} \tanh (\alpha \varepsilon)
$$

with $\varepsilon=\dot{\varepsilon} t$ being strain.

Since $\tau: \mathbf{I}=0$, for an axisymmetric specimen one finds that the lateral deviatoric stresses $\tau_{y y}=\tau_{z z}=-\tau_{x x} / 2$. Then, the longitudinal stress $\sigma_{x x}=\tau_{x x}-\tau_{y y}$ is equal to

$$
\sigma_{x x}=\frac{3 \mu}{\alpha} \tanh (\alpha \varepsilon)
$$

Since as $\varepsilon$ tends to infinity, $\sigma_{x x}=Y$ with $Y$ being the yield stress, and $3 \mu=E$, one finds that $\alpha=E / Y$ and Eq. (A3) reduces to the following expression established by Green: ${ }^{15}$

$$
\sigma_{x x}=Y \tanh \left(\frac{E}{Y} \varepsilon\right),
$$

which obviously recovers Hooke's law $\sigma_{x x}=E \varepsilon$ as $\varepsilon$ tends to zero. 
For uniaxial stretching of a planar strip similar to the experimental situation in the present work, integrating Eq. (A1) and accounting for the fact that $\alpha>1$, we obtain Eq. (1) of the main text, which obviously recovers Hooke's law for this case, $\sigma_{x x}=(4 / 3) E \varepsilon$ as $\varepsilon$ tends to zero.

\section{APPENDIX B: MICROMECHANICS OF NANOFIBER MATS IN UNIAXIAL STRETCHING}

\section{Fiber orientation}

Consider the orientational probability density function $f_{o r}(\varphi, t)$ in nanofiber mats with $\varphi$ being the angle relative to the stretching direction and $t$ being time. It assumes that fiber segments cross any cross-section normal to the stretching direction with certain inclinations $\varphi$, and the corresponding probability density function $f_{o r}(\varphi, t)$ varies in time as stretching goes on. At the moment stretching has begun $t=0$ and $f_{o r}(\varphi, t)=1 /(2 \pi)$ which corresponds to a random mat resulting from solution blowing. The probability density function $f_{o r}(\varphi, t)$ (cf. Fig. 17) can be found from the following FokkerPlanck equation:

$$
\frac{\partial f_{o r}}{\partial t}=\dot{\varepsilon} \frac{\partial}{\partial \varphi}\left(f_{o r} \sin 2 \varphi\right),
$$

where the stretching rate $\dot{\varepsilon}$ is assumed to be constant.

The solution of Eq. (B1) satisfying the initial condition reads

$$
f_{o r}=\frac{\exp (2 \varepsilon)}{2 \pi\left[\cos ^{2} \varphi+\exp (4 \varepsilon) \sin ^{2} \varphi\right]}
$$

It is easy to see that Eq. (B2) automatically satisfies the normalization condition

$$
\int_{0}^{2 \pi} f_{o r} d \varphi=1 .
$$

\section{Rupture of individual bonds in mats under uniaxial stretching}

Tensile strength of different bulk materials $\sigma *$ including individual nanofibers is affected by many factors which are not under control, and therefore can be treated as a mathe-

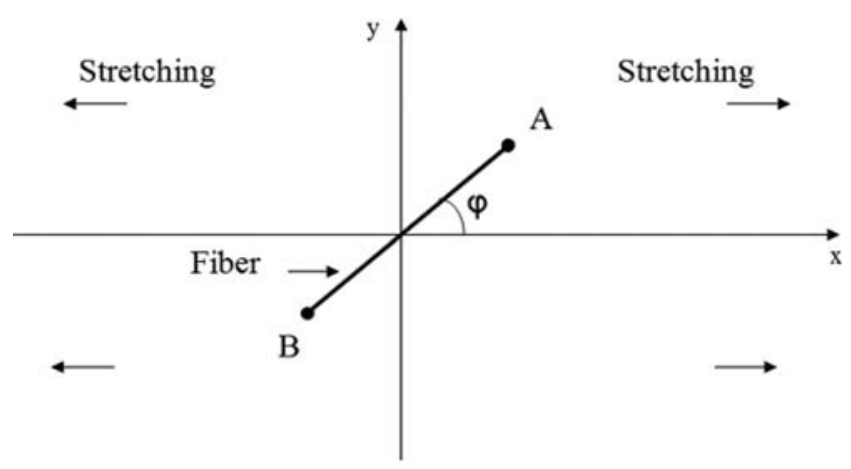

FIG. 17. Randomly oriented fiber with the angle $\varphi$ relative to the stretching direction. matical expectation of many scattered values which might be measured in repeated experiments. Following our previous works, ${ }^{17-19}$ consider a material with $n$ potential defects per unit volume, which might be responsible for a local rupture. In the present context, these defects are associated with the interfiber bonds. These bonds are formed due to conglutination of partially wet nanofibers when they deposit on top of each other in the process of mat forming. The bond strength is random in its nature, albeit an appropriate statistical law can be expected. This law is outlined below. The bonds can be ruptured due to stretching in any direction if an appropriate effective local stress arises. We can treat these bonds as initially conglutinated rupture surfaces (cf. Fig. 18). A bond is ruptured when its banks are pulled apart by an appropriate effective stress normal to its conglutinated surface. Each bond, in fact, can be considered as multiple conglutinated surfaces radiating spherically symmetrically. Any of these surfaces could be ruptured by an appropriate effective normal stress. The bond rupturing process is considered as random.

The calculation below in this subsection follows that of Ref. 19 and is included here for completeness of discussion. The probability density function of a bond to be ruptured by an effective normal stress $\sigma_{11}$ [related to stretching along the $\mathrm{Ox}_{1}$ axis (cf. Fig. 18), whereas the conglutinated surface is normal to this axis] is denoted as $F\left(\sigma_{11}\right)$, and the probability of the defect to be ruptured by a stress from the interval $\left[\sigma_{11}\right.$, $\left.\sigma_{11}+d \sigma_{11}\right]$ is $p_{1}=F\left(\sigma_{11}\right) d \sigma_{11}$. Rupture process in different directions is considered to be mutually independent. Therefore, the number of ruptured bonds in a unit volume subjected to stretching, for example, along three normal axes $\mathrm{Ox}_{1}, \mathrm{Ox}_{2}$, and $\mathrm{Ox}_{3}$ is

$$
d N=n F\left(\sigma_{11}\right) d \sigma_{11} F\left(\sigma_{22}\right) d \sigma_{22} F\left(\sigma_{33}\right) d \sigma_{33} .
$$

This number is obviously associated with the joint probability density function $f\left(\sigma_{11}, \sigma_{22}, \sigma_{33}\right)$, so that

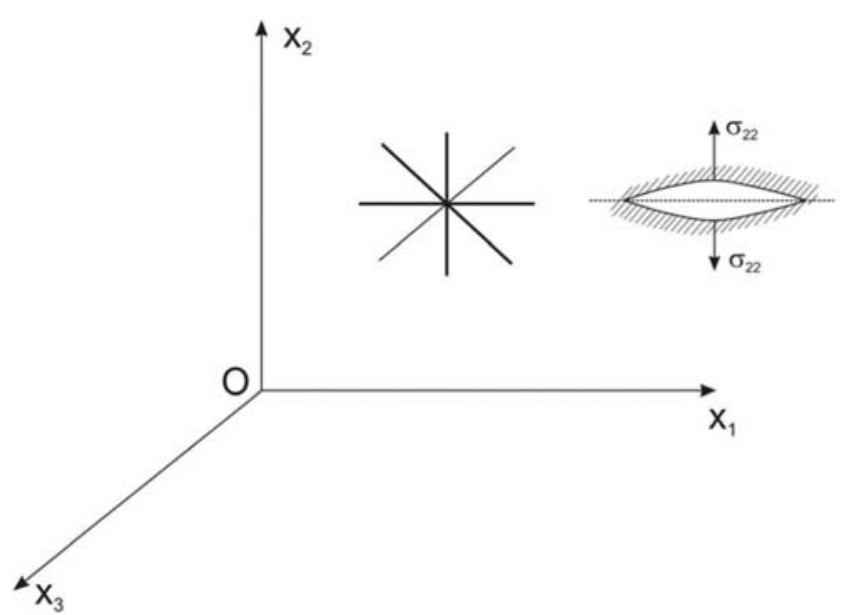

FIG. 18. Sketch of a bond and its rupture. An intact bond with conglutinated banks is depicted on the left. A bond ruptured by stresses in the $x_{2}$ direction is shown on the right. 


$$
\begin{aligned}
d N & =n F\left(\sigma_{11}\right) F\left(\sigma_{22}\right) F\left(\sigma_{33}\right) d \sigma_{11} d \sigma_{22} d \sigma_{33} \\
& =f\left(\sigma_{11}, \sigma_{22}, \sigma_{33}\right) d \sigma_{11} d \sigma_{22} d \sigma_{33} .
\end{aligned}
$$

Therefore, the number of bonds in a unit volume which will not be ruptured at all in such three-axial stretching by stresses $\sigma_{1}, \sigma_{2}$, and $\sigma_{3}$ is given by

$$
\begin{aligned}
N_{0} & =n \int_{\sigma_{1}}^{\infty} F\left(\sigma_{11}\right) d \sigma_{11} \int_{\sigma_{2}}^{\infty} F\left(\sigma_{22}\right) d \sigma_{22} \int_{\sigma_{3}}^{\infty} F\left(\sigma_{33}\right) d \sigma_{33} \\
& =n \Phi\left(\sigma_{1}\right) \Phi\left(\sigma_{2}\right) \Phi\left(\sigma_{3}\right) \\
& =\int_{\sigma_{3}}^{\infty} \int_{\sigma_{2}}^{\infty} \int_{\sigma_{1}}^{\infty} f\left(\sigma_{11}, \sigma_{22}, \sigma_{33}\right) d \sigma_{11} d \sigma_{22} d \sigma_{33} \\
& =\omega\left(\sigma_{1}, \sigma_{2}, \sigma_{3}\right) .
\end{aligned}
$$

Accordingly, the number of bonds ruptured in a unit volume in this case is $N=n-N_{0}$.

The choice of a coordinate system is obviously arbitrary, and same rupture process can be described using an arbitrarily oriented Cartesian coordinate frame $\mathrm{Ox}, \mathrm{Oy}$, and $\mathrm{Oz}$. Then, the number of the intact bonds is equal to $N_{0}=\omega\left(\sigma_{x x}\right.$, $\sigma_{x y}, \sigma_{x z}, \sigma_{y y}, \sigma_{y z}, \sigma_{z z}$, where $\sigma_{x x}$, etc. denote the corresponding components of the effective stress tensor $\boldsymbol{\sigma}$. The previously used Cartesian axes $\mathrm{Ox}_{1}, \mathrm{Ox}_{2}$, and $\mathrm{Ox}_{3}$ can be thought as the principal axes of the effective stress tensor $\boldsymbol{\sigma}$, with $\sigma_{1}$, $\sigma_{2}$, and $\sigma_{3}$ being, correspondingly, the principal stresses. The number of the intact or ruptured bonds should not depend on the directions of the arbitrarily chosen axes $\mathrm{Ox}, \mathrm{Oy}$, and $\mathrm{Oz}$, which means that the function $\omega$ should depend only on the three invariants of the effective stress tensor $\sigma$

$$
\begin{gathered}
I_{1}=\sigma_{x x}+\sigma_{y y}+\sigma_{z z}=\sigma_{1}+\sigma_{2}+\sigma_{3}, \\
I_{2}=\sigma_{x x} \sigma_{y y}+\sigma_{y y} \sigma_{z z}+\sigma_{x x} \sigma_{z z}-\sigma_{x y}^{2}-\sigma_{y z}^{2}-\sigma_{x z}^{2} \\
=\sigma_{1} \sigma_{2}+\sigma_{2} \sigma_{3}+\sigma_{1} \sigma_{3}, \\
I_{3}=\sigma_{x x} \sigma_{y y} \sigma_{z z}+2 \sigma_{x y} \sigma_{y z} \sigma_{x z}-\sigma_{x x} \sigma_{y z}^{2}-\sigma_{y y} \sigma_{x z}^{2}-\sigma_{z z} \sigma_{x y}^{2} \\
=\sigma_{1} \sigma_{2} \sigma_{3} .
\end{gathered}
$$

Equations (B6)-(B9) result in the following functional equation:

$$
\begin{aligned}
n \Phi\left(\sigma_{1}\right) \Phi\left(\sigma_{2}\right) \Phi\left(\sigma_{3}\right)= & \omega\left(\sigma_{1}+\sigma_{2}+\sigma_{3}, \sigma_{1} \sigma_{2}+\sigma_{2} \sigma_{3}\right. \\
& \left.+\sigma_{1} \sigma_{3}, \sigma_{1} \sigma_{2} \sigma_{3}\right) .
\end{aligned}
$$

Its solution reads

$$
\Phi\left(\sigma_{i}\right)=\left(A+B \sigma_{i}\right) \exp \left(-C \sigma_{i}\right), \quad i=1,2,3,
$$

with $A, B$, and $C$ being constants.

When there is no stress applied, the number of the intact bonds in a unit volume $N_{0}=n$. Then, Eqs. (B10) and (B11) yield $N_{0}=n A,{ }^{3}$ and therefore, $A=1$.

From Eq. (B11), it follows that

$$
\varphi\left(\sigma_{i}\right)=\int_{\sigma_{i}}^{\infty} F\left(\sigma_{i i}\right) d \sigma_{i i}=\left(1+B \sigma_{i}\right) \exp \left(-C \sigma_{i}\right),
$$

which yields

$$
F\left(\sigma_{i i}\right)=\left(B C \sigma_{i i}+C-B\right) \exp \left(-C \sigma_{i i}\right) .
$$

Since materials have a certain strength, $F(0)=0$, and thus $C=B$, which results in

$$
F\left(\sigma_{i i}\right)=B^{2} \sigma_{i i} \exp \left(-B \sigma_{i i}\right) .
$$

It is easy to see that Eq. (B14) satisfies the normalization condition.

The mathematical expectation of the bond-opening stress is denoted $\sigma_{*}$. Therefore, using Eq. (B14), we obtain

$$
\sigma_{*}=\int_{0}^{\infty} \sigma_{i i} F\left(\sigma_{i i}\right) d \sigma_{i i}=\int_{0}^{\infty} B^{2} \sigma_{i i}^{2} \exp \left(-B \sigma_{i i}\right) d \sigma_{i i},
$$

which yields $B=2 / \sigma_{*}$. Then, the probability density function of bond rapture under stretching in the $i$-th direction is given by

$$
F\left(\sigma_{i i}\right)=\frac{4}{\sigma_{*}^{2}} \sigma_{i i} \exp \left(-2 \sigma_{i i} / \sigma_{*}\right) .
$$

\section{Mat plasticity as bond rupture process}

Assume that all bonds behave as Hookean elastic solids until they rupture. We aim to show below that the macroscopic nanofiber mat plasticity can result from rupture of individual bonds in the mat under uniaxial stretching.

Fibers in the mat experience different stretching from the overall macroscopic axial stretching imposed on the sample $\epsilon$. Indeed, for an inclined fiber the strain $\varepsilon_{i}$ is given by

$$
\varepsilon_{i}=\varepsilon \cos ^{2}(\varphi) .
$$

According to Eq. (B16), if an initially unloaded bond was stretched to a certain stress $\sigma$, its probability to stay intact $\mathrm{P}_{\text {intact }}$ is

$$
P_{\text {intact }}=\left(1+\frac{2 \sigma}{\sigma_{*}}\right) \exp \left(-\frac{2 \sigma}{\sigma_{*}}\right)
$$

Then, it is easy to see that the longitudinal stress in the mat is given by the following expression:

$$
\sigma_{x x}=E_{m} \int_{0}^{2 \pi} \varepsilon_{i}(\varphi) \cos ^{2} \varphi P_{\text {intact }} f_{o r}(\varphi, \varepsilon) d \varphi,
$$

where $E_{m}$ is proportional to Young's modulus.

Substituting Eqs. (B2), and (B17) into Eq. (B19), and accounting for the fact that for an individual Hookean bond according to Eq. (B17) $\sigma=E_{f} \epsilon \cos ^{2} \varphi$ with $E_{f}$ being the characteristic Young's modulus, we arrive at Eq. (2) of the main text.

${ }^{1}$ D. L. Klass, Biomass for Renewable Energy, Fuels, and Chemicals (Academic, New York, 1998).

${ }^{2}$ I. Ahmed, J. Decker, and D. Morris, "How Much Does it Take to Make a Gallon of Soydiesel?" in Report for the National SoyDiesel Development Board, Jefferson, Missouri (1994).

${ }^{3}$ J. Zhang, P. Mungara, and J. Jane, Polymer 42, 2569 (2001).

${ }^{4}$ S. Sinha-Ray, Y. Zhang, A. L. Yarin, S. Davis, and B. Pourdeyhimi, Biomacromolecules 12, 2357 (2011).

${ }^{5}$ A. Vega-Lugo and L. Lim, Food Research International 42, 933 (2009).

${ }^{6}$ A. J. Poole, J. S. Church, and M.G. Huson, Biomacromolecules 10, 1 (2009). 
${ }^{7}$ D. Cho, O. Nnadi, A. Netravali, and Y. L. Joo, Macromol. Mater. Eng. 295, 763 (2010).

${ }^{8}$ M. Phiriyawirut, N. Rodchanacheewa, N. Nensiri, and P. Supaphol, Advanced Materials Research 55-57, 733 (2008).

${ }^{9}$ S. Sinha-Ray, A. L. Yarin, and B. Pourdeyhimi, J. Appl. Phys. 108, $034912(2010)$.

${ }^{10}$ S. Sinha-Ray, A. L. Yarin, and B. Pourdeyhimi, Carbon 48, 3575 (2010).

${ }^{11}$ W. Prager, Proc. $5^{\text {th }}$ Int. Congr. Appl. Mech., Cambridge, Mass. 234 (1938).

${ }^{12}$ W. Prager, Duke Math. J. 9, 228 (1942).
${ }^{13}$ C. Truesdell, J. Rat. Mech. Anal. 1, 125 (1952).

${ }^{14}$ C. Truesdell, J. Rat. Mech. Anal. 2, 593 (1953).

${ }^{15}$ A. E. Green, Proc. Roy. Soc. London A234, 46 (1956).

${ }^{16}$ M. B. Rubin and A. L. Yarin, J. Non-Newton. Fluid Mech. 50, 79 (1993);

Corrigendum: J. Non-Newton. Fluid Mech. 57, 321 (1995).

${ }^{17}$ V. B Librovich and A. L. Yarin, Combustion, Explosion and Shock Waves 18, 547 (1982).

${ }^{18}$ V. B. Librovich and A. L. Yarin, Archivum Combustionis 8, 79 (1988).

${ }^{19}$ A. L. Yarin, Mathematical Modelling of Natural Phenomena 3, 1 (2008). 